\title{
ANNONA CORIACEA INDUZ EFEITO GENOTÓXICO EM CAMUNDONGOS
}

\author{
Annona coriacea induces genotoxic effect in mice
}

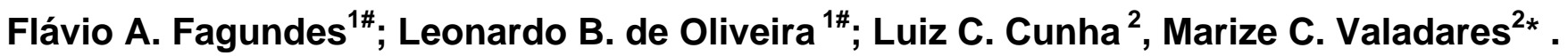 \\ ${ }^{1}$ Graduando em Farmácia, Faculdade de Farmácia, Universidade Federal de Goiás, Goiânia, GO, Brasil \\ ${ }^{2}$ Prof. Adjunto da Faculdade de Farmácia, Universidade Federal de Goiás, Goiânia, GO, Brasil
}

*Autor para correspondência: e-mail: marizecv@farmacia.ufg.br

Recebido em 09/05/2005 - aceito em 04/07/2005

RESUMO: Este estudo foi realizado para investigar a toxicidade genética da Annona coriacea utilizando o teste de micronúcleo de eritrócitos da medula óssea. Os resultados demonstraram que o extrato alcoólico das sementes desta planta, nas diferentes doses utilizadas $(50,100,200$ ou $400 \mathrm{mg} / \mathrm{kg}$ ) induziu um aumento significativo na freqüência de micronúcleos nos eritrócitos da medula óssea de camundongos, quando comparado ao controle negativo. Além disso, este aumento foi similar a aquele encontrado nos animais expostos ao controle positivo (ciclofosfamida, 250mg/kg). Estes resultados sugerem que esta planta, nas condições experimentais avaliadas, possui um potencial significativo para induzir danos ao DNA.

PALAVRAS-CHAVE: toxicologia genética, micronúcleo, araticum, Annona coriacea

ABSTRACT: This study was designed to evaluate the genetic toxicity of the Annona coriacea using the bone marrow erythrocyte micronucleus test. The results demonstrated that the seed alcoholic extract of this plant, in different doses used $(50,100,200$ or $400 \mathrm{mg} / \mathrm{kg})$ induced a significant increase in micronucleus frequencies in bone marrow erythrocytes of mice, when compared to the negative control. In addition, this increase was similar to those found in the group of mice exposed to the positive control (cyclophosphamide $250 \mathrm{mg} / \mathrm{kg}$ ). These results suggest that this plant, in this experimental condition, has a significant potential for induce DNA damage.

KEYWORDS: genetic toxicology, micronuclei, araticum, Annona coriacea

\# Os dois autores tiveram participação equivalente na elaboração do trabalho

\section{INTRODUÇÃO}

O estudo de danos ao DNA induzido por substancias de origem natural ou sintética é uma área essencial da toxicologia genética uma vez que mutação em cromossomos é um evento importante na carcinogênese (FENECH, et al., 2005). Por outro lado, compostos antitumorais clássicos como a ciclofosfamida são reconhecidamente como um agente potencialmente genotóxico.

Dentre os testes de avaliação de genotoxicidade preconizados pelas agências internacionais e instituições governamentais, o teste de micronúcleo em medula óssea de roedores in vivo é amplamente aceito e recomendado para a avaliação e o registro de novos produtos químicos e farmacêuticos que entram anualmente no mercado mundial (CHOY, 2001, RIBEIRO, et al., 2003).

Os micronúcleos originam-se de fragmentos cromossômicos acêntricos, produzidos por quebras cromossômicas, ou ainda de cromossomos inteiros que sofrem retardo em relação aos demais, durante a migração para os pólos da célula em anáfase durante a divisão celular. A avaliação da incidência de micronúcleos vem sendo amplamente utilizada para detectar dano cromossômico estrutural. EVANS e colaboradores (1959) usaram a freqüência de micronúcleos para medir o dano citogenético induzido em plantas por irradiações. HÖGSTEDT e colaboradores (1981) demonstraram in vivo a ação citogenética de diversas substâncias no 
esfregaço de medula óssea por meio do teste de micronúcleos (HÖGSTEDT, 1981a e b). Na década de 70, o teste de micronúcleos tornou-se viável e confiável pelo estudo de eritrócitos policromáticos da medula óssea em camundongos, passando a ser um dos mais úteis indicadores de dano citogenético na medula óssea (HEDDLE, 1973a e b, SCHMID, 1975).

Mais recentemente, o teste de micronúcleo emergiu como um dos métodos recomendados para avaliar os danos do cromossomo, uma vez que este método permite a avaliação confiável tanto da perda quanto da ruptura do cromossomo, (FENECH, 2005). Este teste é capaz de revelar a ação de agentes clastogênicos (que quebram cromossomos) e aneugênicos (que induzem aneuploidia ou segregação cromossômica anormal) (MAC GREGOR et al.,1987). Conseqüentemente, a comparação da freqüência de micronúcleos entre populações de células em divisão só seria segura quando a cinética de divisão nuclear, pós o dano ao DNA, fosse idêntica (FENECH, et al., 1997).

A família das anonáceas engloba uma grande variedade de espécies frutíferas. As plantas desta família caracterizam-se por apresentarem folhas simples, dispostas alternadamente em um mesmo plano, ao longo dos ramos e pela semelhança entre seus frutos (ALMEIDA, et al., 1998).

Araticum-do-cerrado é o nome dado a diferentes espécies de anonáceas encontradas nos cerrados da região central do Brasil. Como marolo, é conhecido por todo o sul de Minas Gerais, onde são nativos e espontâneos nos enclaves de campos cerrados existentes na região, sendo a fruta amplamente consumida e apreciada pela população (ALMEIDA, et al., 1998). Além disso, esta planta (folhas e sementes) é empiricamente empregada no tratamento de doenças como processos inflamatórios.

As anonáceas são largamente empregadas na etnofarmacologia devido às suas diferentes propriedades farmacológicas atribuídas principalmente as acetogeninas, um dos principais constituintes bioativos encontrados em gêneros específicos das anonáceas (ALALI \& LIU, 1999; KOTAKE \& OHTA, 2003; BERMEJO et al., 2005 ;).

Estudos na literatura demonstraram que a Annona coriacea (Figura 1) possui acetogeninas específicas de grande potencial citotóxico (MENESES DA SILVA, et al., 1996). Neste sentido, resultados preliminares em nosso laboratório indicam atividade citotóxica significativa contra células da medula óssea de camundongos.

As acetogeninas possuem diversas atividades biológicas relatadas na literatura como, por exemplo, antitumoral, imunossupressor, pesticida, antiprotozoário, anti-helmíntico e antimicrobiano, o que fez deste constituinte bioativo objeto de inúmeras pesquisas. Sobre as acetogeninas, foi relatado que podem inibir seletivamente o crescimento de células cancerosas e também de inibir o crescimento de células tumorais resistentes a adriamicina, demonstarndo extraordinária seletividade entre certas linhagens celulares, especificamente, contra câncer prostático (ALALI \& LIU, 1999; KOTAKE \& OHTA, 2003; BERMEJO et al., 2005;).

As acetogeninas são potentes inibidoras da NADH ubiquinona oxidorredutase, que é uma enzima essencial no complexo I levando a uma fosforilação oxidativa na mitocôndria da célula. Estudo na literatura demonstrou que estas substâncias agem diretamente no sítio catalítico da ubiquinona, dentro do complexo I e na glicose desidrogenase microbiana. Elas inibem também a NADH oxidase ligada a ubiquinona, peculiar às membranas plasmáticas das células cancerosas (ALALI \& LIU, 1999; KOTAKE \& OHTA, 2003; BERMEJO et al., 2005;).

Recentemente, trabalhos na literatura têm associado ao consumo de anonáceas pela população com o aparecimento de neurotoxicidade e conseqüentemente uma doença similar ao parkisonismo. Tal efeito neurotóxico tem sido atribuído às acetogeninas (CHAMPY, et al., 2004).

Diante do exposto, neste trabalho investigamos o efeito do extrato alcoólico das sementes da Annona coriacea, uma espécie de araticum-do-cerrado, sobre a incidência de micronúcleos em camundongos expostos a diferentes concentrações do extrato desta planta.

A

B
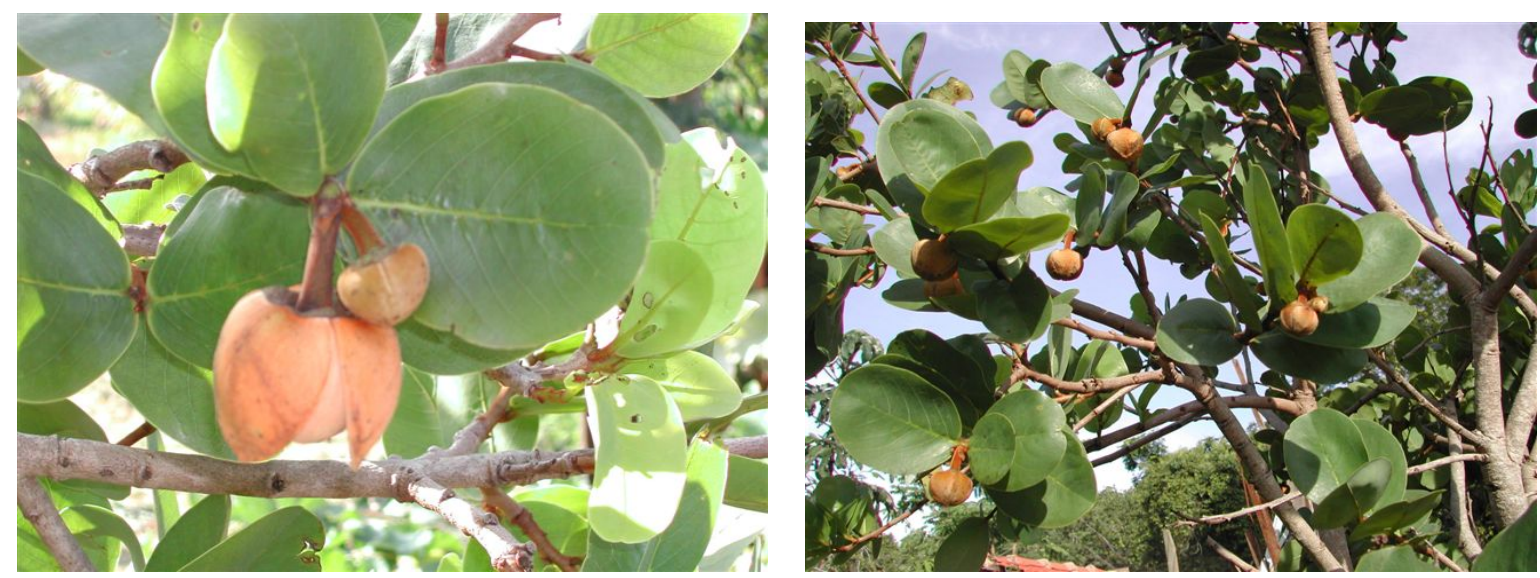

Figura 1- Annona coriacea do cerrado goiano: A (inflorescência), B (folhas e porte da planta). 


\section{MATERIAL E MÉTODOS}

\section{Annona coriacea}

O material botânico foi colhido no cerrado das proximidades da cidade de Goiânia, Goiás. Foi preparada exsicata do material, contendo caule, folhas, flores e frutos, para identificação botânica. Todos os reagentes, soluções e solventes foram de grau analítico com laudo de qualidade apresentado pelo fabricante.

Os frutos foram colhidos tendo as sementes retiradas e colocadas em estufa de secagem ventilada durante uma semana a $40^{\circ} \mathrm{C}$. Após a secagem total, as sementes foram trituradas para a preparação do extrato. Foram feitas três extrações alcoólicas da mesma massa triturada, sendo que a cada $100 \mathrm{~g}$ de massa das sementes trituradas, adicionou-se $500 \mathrm{~mL}$ de álcool etílico 70\%. A mistura foi agitada mecanicamente por $5 \mathrm{~h}$ e logo em seguida foi filtrada. Os três filtrados foram misturados e levados para concentração do extrato em rotaevaporador onde se recuperou o álcool usado. O concentrado foi liofilizado na empresa Doles Reagentes e Equipamentos para Laboratório LTDA (BR 153 Km 1273 Gôiania - GO 74001-970).

\section{Animais}

Para a realização dos experimentos foram utilizados camundongos Swiss com idade entre 7 a 12 semanas, fornecidos pela Indústria Química do Estado de Goiás (IQUEGO). Os animais foram mantidos agrupados ao acaso em gaiolas plásticas, em sala climatizada sob temperatura constante de $26 \pm 2^{\circ} \mathrm{C}$, com ciclo claro-escuro de $12 \mathrm{~h}$. O regime alimentar foi o clássico, com ração comercial padrão e água fornecida ad libitum. Os animais foram divididos em grupos e submetidos aos tratamentos. Os experimentos com animais foram realizados de acordo com o protocolo institucional e diretriz do Conselho Canadense sobre uso de animais (OLFERT, et al., 1993)

\section{Avaliação do potencial mutagênico do extrato das sementes da Annona coriacea}

Para a avaliação do potencial mutagênico foi feita uma administração oral nos camundongos, de diferentes concentrações do extrato $(50,100,200$ ou $400 \mathrm{mg} / \mathrm{kg})$. O extrato foi diluído para obtenção da dosagem em tween 80 e salina estéril (1:10). Em cada animal administrou-se um volume final de 0,2 $\mathrm{ml}$ da solução correspondente a dose determinada por grupo. Vinte e quatro horas após o tratamento os animais foram sacrificados por deslocamento cervical e, então, a medula óssea dos 2 fêmures foram colhidas para o preparo das lâminas e a pesquisa de micronúcleos. Neste experimento, utilizamos a ciclofosfamida como controle positivo.

Os grupos de tratamentos ficaram assim distribuídos:

a) Grupo I: controle que recebeu o solvente da droga

b) Grupo II: controle sem tratamento

c) Grupo III: animais que receberam $50 \mathrm{mg} / \mathrm{kg}$

d) Grupo IV: animais que receberam $100 \mathrm{mg} / \mathrm{kg}$

e) Grupo V: animais que receberam $200 \mathrm{mg} / \mathrm{kg}$

f) Grupo Vl: animais que receberam $400 \mathrm{mg} / \mathrm{kg}$

g) Grupo VII: animais que receberam ciclofosfamida (controle positivo, 250mg/kg)

\section{Preparo das lâminas para pesquisa de micronúcleo}

A medula óssea foi coletada com o auxílio de uma seringa de $1 \mathrm{ml}$ preenchida com salina. $\mathrm{O}$ fêmur foi lavado com a salina e a suspensão celular foi coletada em um tubo de ensaio contendo salina. A suspensão celular foi centrifugada por 5 minutos a 2000rpm descartando-se, depois, o sobrenadante e conservando um volume de $0,5 \mathrm{ml}$ deste no tubo para posterior ressuspensão e homogeneização do precipitado celular.

Da suspensão resultante, uma pequena gota foi retirada e colocada numa das extremidades da lâmina para a realização do esfregaço. Após a secagem do esfregaço, este foi corado com Leishmann e as lâminas secas à temperatura ambiente. Depois de secas, aplicou-se uma gota pequena de Bálsamo do Canadá no centro da lâmina para a fixação da lamínula.

\section{Análise estatística}

Os dados foram avaliados utilizando o método estatístico de Análise de Variância (ANOVA) e o teste a posteriori de Tukey. 


\section{RESULTADOS E DISCUSSÃO}

Na figura 2 estão representados os dados obtidos da formação de micronúcleos em animais expostos ao quimioterápico clássico ciclofosfamida. Como já esperado, nossos resultados corroboram os dados da literatura demonstrando o efeito genotóxico desta droga, expresso pelo aumento da incidência de micronúcleos, quando comparado ao grupo controle sem tratamento $(P<0,05$; ANOVA, teste Tukey).

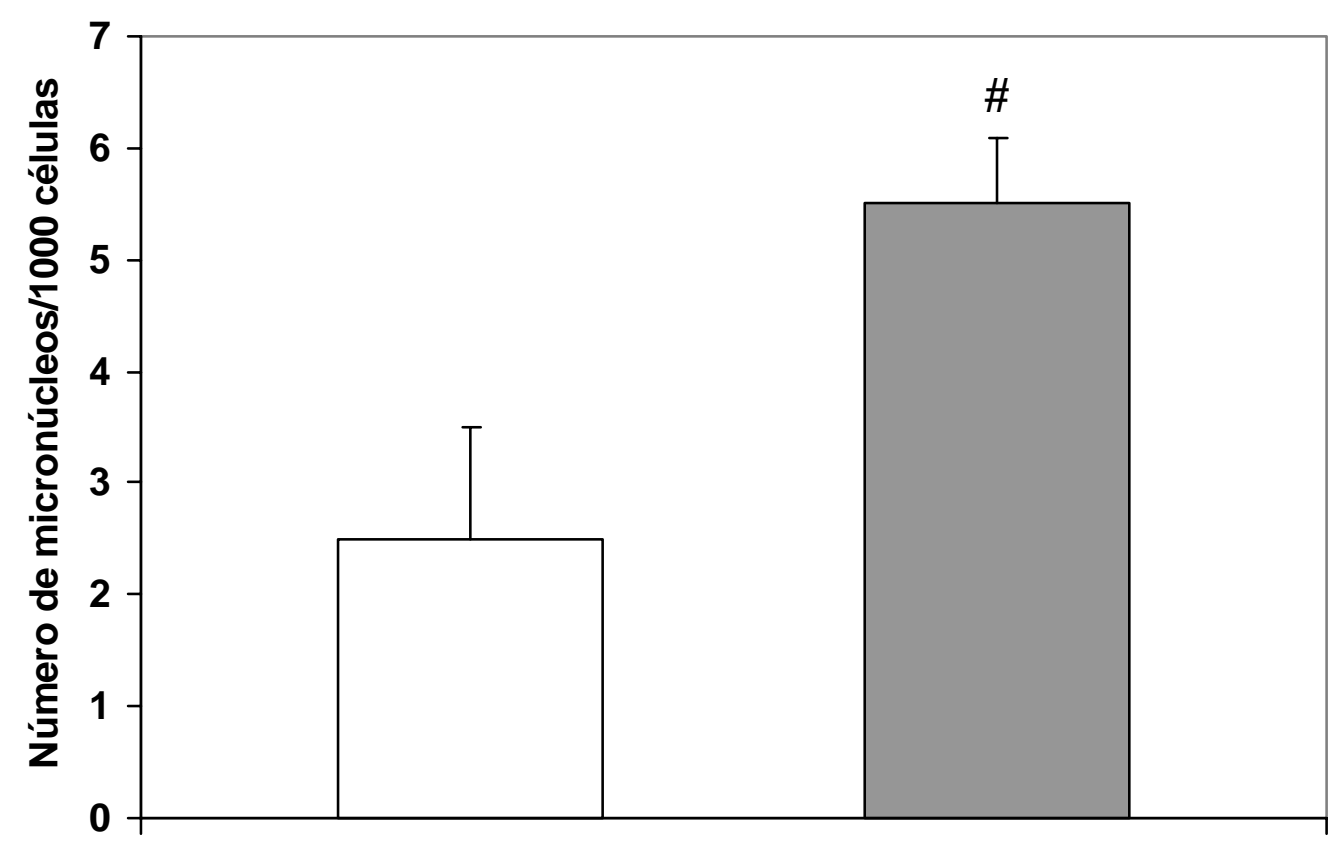

$\square$ Controle

$\square$ Ciclofosfamida

Figura 2- Avaliação da incidência de micronúcleos em animais expostos a ciclofosfamida. A formação e o número de micronúcleos foram analisados em 1000 eritrócitos. Chave: ${ }^{\#} P<0,05 ;$ ANOVA, teste Tukey.

Conforme mostrado na figura 3 , nossos resultados demonstraram que a exposição de animais normais às diferentes concentrações $(50,100,200$ e $400 \mathrm{mg} / \mathrm{kg}$ ) do extrato alcoólico das sementes da Annona coriacea induziu de forma significativa um aumento na incidência de micronúcleos, quando comparado ao grupo de animais controle que somente receberam o solvente da droga $(P<0,05$; ANOVA, teste Tukey). Este aumento da formação de micronúcleos se deu de forma independente das doses utilizadas, ou seja, todas as doses empregadas neste estudo induziram o aumento de incidência de formação de micronúcleos e nenhuma diferença estatística foi detectada entre as doses utilizadas. Ademais, os valores encontrados são similares àqueles encontrados no grupo de animais expostos à ciclofosfamida.

A idéia de que alimentos de origem natural possuem importantes propriedades no combate contra o desenvolvimento de doenças, em particular o câncer, é amplamente difundida pela comunidade científica e muito bem aceita pela população em geral. No entanto, a possibilidade destes alimentos possuírem efeitos adversos tem sido negligenciada e até mesmo ignorada (STOPPER, et al., 2005). Diante disto, estudos na literatura indicam que diferentes produtos de origem natural como alguns flavonóides da soja, genisteína, daidzeína e metabólitos, amplamente utilizados nos últimos tempos, podem ser potencialmente genotóxicos (SCHMITTA et al., 2003). Os mecanismos envolvidos que explicam a clastogenecididade e/ou interação com o DNA não estão totalmente elucidados. Segundo Schmitta e colaboradores, 2003, a segurança ou toxicidade da utilização destes produtos de origem natural dependem do tempo de exposição da dose utilizada.

Dentre os testes de avaliação de danos sobre o DNA em células in vitro, o teste de micronúcleo em medula óssea de camundongos tem sido largamente utilizado para estabelecer correlação entre carcinogênese e a dieta do individuo (AZEVEDO, et al., 2003). A relação entre o alimento e o câncer, bem como o conhecimento de que o câncer pode ser prevenido, resultou no aumento do interesse em alimentos mutagênicos ou potencialmente anti-mutagênicos (AZEVEDO et al., 2003).

O micronúcleo é um método utilizado para avaliar a capacidade de substâncias para induzir danos cromossômicos em células em estágio de divisão na medula óssea (FENECH, 2005). Desta forma, como já esperávamos, nossos resultados demonstraram que a freqüência de micronúcleos nos grupos de camundongos que foram expostos à ação do agente genotóxico ciclofosfamida é significativamente maior em comparação ao 
grupo controle (controle negativo, tratado com o solvente da droga), o que corrobora dados da literatura. Além disso, verificamos ainda que a exposição de animais normais às diferentes concentrações $(50,100,200$ e $400 \mathrm{mg} / \mathrm{kg}$ ) do extrato alcoólico das sementes da Annona coriacea induziu de forma significativa um aumento na incidência de micronúcleos, quando comparado ao grupo de animais controle que somente receberam o solvente da droga. Este evento foi verificado em todas as doses empregadas neste estudo. Ademais, em um outro experimento verificamos a exposição dos animais ás diferentes concentrações desta planta e $24 \mathrm{~h}$ após expostos à ciclofosfamida, não modificou a incidência de micronúcleos, quando comparado aos animais somente expostos à ciclofosfamida (dados não apresentados). O que nos permite concluir neste ensaio que a exposição ao agente genotóxico a posteriori não induziu efeito aditivo sobre a incidência de micronúcleos nos animais expostos à planta. Estes dados em conjunto nos permitem sugerir que o extrato das sementes da Annona coriacea produziu instabilidade genômica sobre as células da medula óssea de camundongos normais. Além disso, estudo em andamento em nosso laboratório demonstrou um importante efeito citotóxico do extrato desta planta sobre as células da medula óssea de camundongos normais.

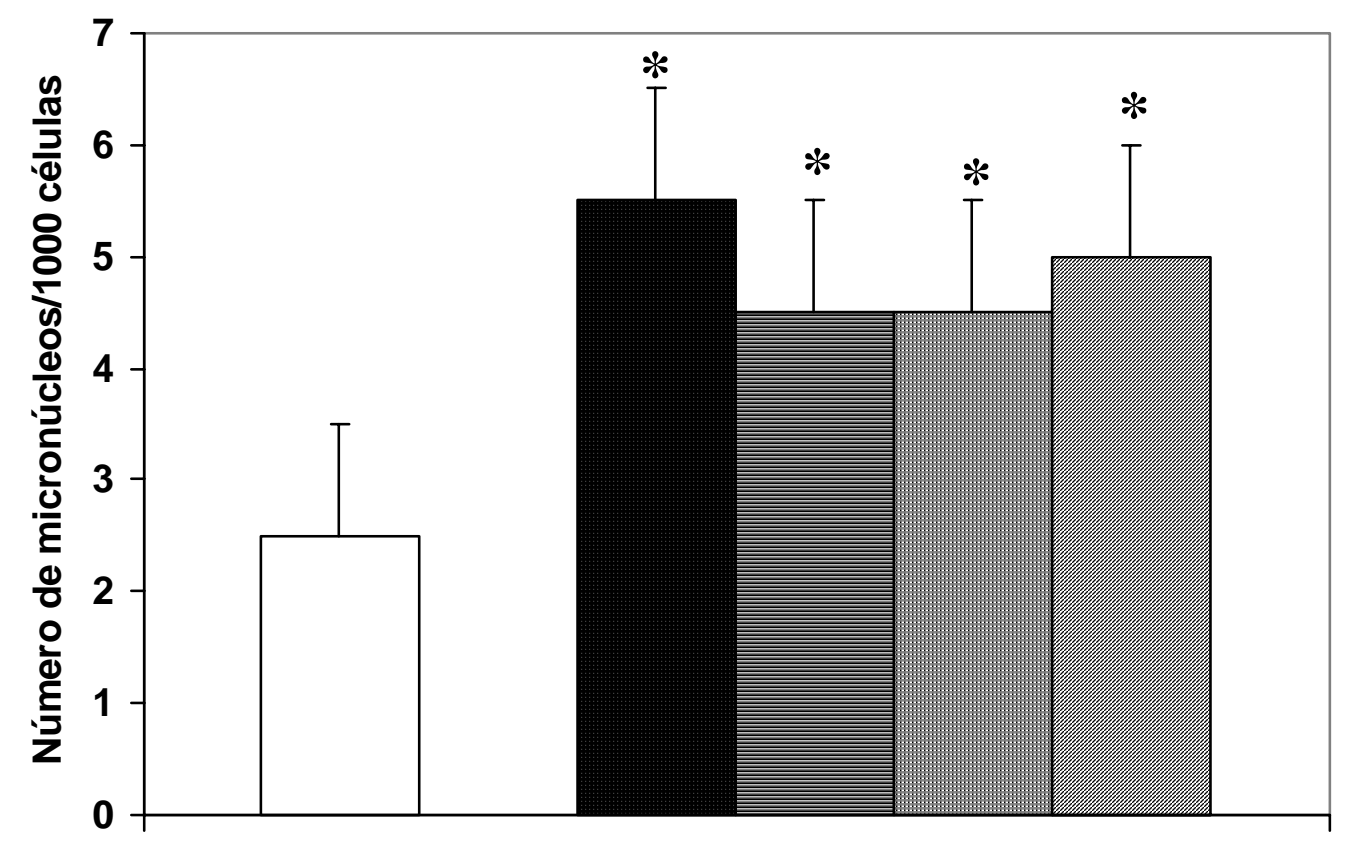

\section{$\square$ Controle $\square 50 \mathrm{mg} / \mathrm{kg} \quad$ 目 $100 \mathrm{mg} / \mathrm{kg} \quad \square 200 \mathrm{mg} / \mathrm{kg} \quad \square 400 \mathrm{mg} / \mathrm{kg}$}

Figura-3. Avaliação da incidência de micronúcleos em animais expostos a diferentes concentrações (50, 100, 200 ou $400 \mathrm{mg} / \mathrm{kg}$ ) do extrato das sementes de Annona coriacea. A formação e o número de micronúcleos foram analisados em 1000 eritrócitos. Chave: * $P<0,05$; ANOVA, teste Tukey.

\section{CONCLUSÃO}

Embora não tenha sido detectado um acréscimo proporcional da freqüência de micronúcleo em relação ao aumento da dose administrada, ficou claro a capacidade do extrato das sementes Annona coriacea de causar alterações no DNA, caracterizando-o como um agente potencialmente genotóxico. Maiores estudos utilizando outras doses deverão ser realizados com o objetivo de confirmar os efeitos genotóxicos da Annona coriacea, além de indicar os mecanismos envolvidos que explicam a clastogenecididade e/ou interação com o DNA demonstrado por esta planta.

\section{AGRADECIMENTOS}

À empresa Doles Reagentes e Equipamentos para Laboratório LTDA (BR 153 Km 1273 Gôiania - GO 74001-970) pela disponibilidade na liofilização do extrato. 


\section{REFERÊNCIAS BIBLIOGRÁFICAS}

ALALI, F. Q.; LIU, X. X.; MCLAUGHLIN, J. L. Annonaceous acetogenins: recent progress. J Nat Prod., 62, 504-40, 1999.

ALMEIDA, S. P.; PROENÇA, C. E. B.; RIBEIRO, J. F. Cerrado espécies vegetais úteis. Planatina, Distrito Federal, Editora da Embrapa, 1998.

AZEVEdo, L. A. J. C.; GOMESB, P. C.; STRINGHetAB, Á. M. M. C.; GONTIJOC, C. R.; PADOVANID, L. R.; RIBEIRO D. M. F. et al., Black bean (Phaseolus vulgaris $L$.) as a protective agent against DNA damage in mice. Food and Chemical Toxicology 41, 1671-1676, 2003.

BERMEJO, A.; FIGADERE, B.; ZAFRA-POLO, M. C.; BARRACHINA, I.; ESTORNELL, E.; CORTES, D. Acetogenins from Annonaceae: recent progress in isolation, synthesis and mechanisms of action. Nat Prod Rep. 22, 269-303, 2005.

CHAMPY, P.; HOGLINGER, G. U.; FEGER, J.; GLEYE, C.; HOCQUEMILLER, R.; LAURENS, A.; et al., .Annonacin. A lipophilic inhibitor of mitochondrial complex I, induces nigral and striatal neurodegeneration in rats: possible relevance for atypical parkinsonism in Guadeloupe. J Neurochem. 88, 63-9. 2004

CHOY, W. N. Regulatory genetic toxicology tests. Genetic Toxicology and Cancer Risk Assessment (Choy, W. N. ed.), Marcel Dekker, Inc, New York,. 93-113, 2001.

EVANS, H. J.; NEARY, G.J.; WILLIAMSON, F. S.The relative biological efficiency of single doses of fast neutrons and gamma rays on vicia fasba roots and the effect of oxygen. Int. J radiation Biol; 1:216-29, 1959.

FENECH, M. In vitro micronucleus technique to predict chemosensitivity. Methods Mol Med.;111: 3-32, 2005.

FENECH, M. The advantages and disasdvantages of the cytokinesis-block micronucleus method. Mutation Research, 392: 11-18, 1997.

HEDDLE, J. A. A rapid in vivo test for chromosomal damage. Mutation Research 18:1870190, 1973 a.

HEDDLE, J. A. A rapid in vivo test for chromosomal damage. Mutation Research, 18, 187-190, 1973 b.

HÖGSTEDT, B.; GULLBERG, B.; MASRK-VENDEL, E.; MITELMAN, F. G.; SKERFVING, S. Micronuclei and chromosome aberrations in bone marrow cells and lymphocytes of humans exposed mainly to petroleum vapors. Hereditas; 94:179-187, 1981a.

HÖGSTEDT, B.; NILSSON, P. G.; MITELMAN, F. Micronuclei in erytropoetic bone marrow cells: relation to cytogenetic pattern and prognosis in acute nonlymphocytic leukemia. Cancer Genet Cytogenet; 3:185-193. 1981b.

MACGREGOR, J.T.; HEDDLE, J.A.; HITE, M.; MARGOLIN, B.H; RAMEL, C.; SALAMONE, M.F.; TICE, R.R.; WILD, D. Guidelines for the conduct of micronucleus assay in mammalian bone marrow erythrocytes. Mutation Research, .189, 103-112, 1987.

MENESES DA SILVA, E. L.; ROBLOT, F.; MAHUTEAU, J.; CAVE, A. Coriadienin, the first annonaceous acetogenin with two double bonds isolated from Annona coriaceae. Nat Prod. 59, 528-30. 1996

OLFERT ED, CROSS BM, MCWILLIAM AA. In: Guide to the care and use of experimental animals. Canadian Council on Animal Care, Ottawa, 1, 1-11. 1993:

RIBEIRO, L. R.; SALVADORI, D. M. F.; MARQUES, E. K. Mutagênese Ambiental. Editora da ULBRA, Edição Única, 173-198, 2003.

SCHMID, W. The micronuclei test. Mutation Research; 31:9-15, 1975.

SCHMITTA, E. M. M.; JONASA, R.; DEKANTA, W.; STOPPER, H. Genotoxic activity of four metabolites of the soy isoflavone daidzein. Mutation Research/Genetic Toxicology and Environmental Mutagenesis, 542, 43-48, 2003.

STOPPER, H.; SCHMITT, E.; KOBRAS, K. Genotoxicity of phytoestrogens. Mutat Res. 57, 139-55. 2005. 
Fagundes F. A., et al./Revista Eletrônica de Farmácia vol. 2 (1), 24-29, 2005.

KOTAKE, Y.; OHTA, S. MPP+ analogs acting on mitochondria and inducing neuro-degeneration. Curr Med Chem., 10, 2507-16, 2003. 